\title{
A Research of Big Data's Push on Innovation of Social Governance
}

\author{
Wang Tingjin $1^{*}$ \\ School of Public Finance and \\ Management, Yunnan University Of Finance and \\ Economics. Kunming, P.R.China 650221 \\ 810765291@qq.com
}

\author{
Han Quanfang 2 \\ School of Public Finance and \\ Management, Yunnan University Of Finance and \\ Economics. Kunming, P.R.China 650221 \\ Hqfang666@163.com
}

\begin{abstract}
In the era of big data, great changes have taken place in thoughts and modes of social governance. As the fundamental element to promote social innovation and reform, big data provides new opportunity for innovation of social governance system modes and methods, meanwhile it brings new challenges with varying level. Therefore we must enhance awareness of strategic opportunity and make efforts to innovate new pathway for big data to promote social governance.
\end{abstract}

Key words : big data; social governance; innovative strategy

With the rapid development of informatization, human beings enter the age of big data. Big data brings revolutionary changes to every field and all walks of life in society, profoundly changes our thinking mode of the world, and improves our ability to transform the world, which has become the fundamental element to promote innovation and reform of national governance as well as social governance. The third plenary sessions of the Central Committee of the 18th CPC National Congress proposed, "the overall goal of comprehensively deepening reform is to improve and develop the socialist system with Chinese characteristics, and to modernize the country's governance system and governance capability." The fifth plenary sessions of the Central Committee of the 18th CPC National Congress again emphasized the implementation of national bid data strategy, and further put forward the development goal of strengthening and innovating social governance, promoting the refinement of social governance, and constructing the social governance pattern shared by all, which required the subject of social governance to accelerate the application of big data thoughts and technologies, constantly innovate ideas and modes of social governance, and realize the modernization of social governance capability progressively.

Big data has attracted worldwide attention due to its volume, varity, velocity, and value, and has gradually become an effective way to support social governance innovation.so we must earnestly enhance our strategic vision and awareness of opportunities, and be good at grasping the new opportunities and challenges brought by social governance in the era of big data so that we can better win opportunities and initiatives. It can also deepen social governance innovation at a higher level.

\section{NEW OPPORTUNITIES OF SOCIAL GOVERNANCE INNOVATION IN BIG DATA ERA}

A.Big data provides technical support for precise decision making.

As the most advanced information technologies, Internet of Things, big data and cloud computing have become effective tools of social governance, which need cooperation of the above-mentioned three technologies, i.e. big data is acquired by Internet of Things, and analysis of big data depends on technologies like cloud computing to provide technical support for intelligent governance.

\section{B.Big data contributes to the shift from fragmented} governance to gridding governance

Recently, self governance, lack of coordination, and function and management overlapping of government and each subject of social governance inevitably lead to the 
embarrassment of high governance cost and low efficiency. In the context of big data age and applications of relevant technologies, all subjects of social governance including the government should further expand the collection channels of big data and information, enhance collaborative governance between governments and departments with big data management thoughts, establish the open and shared philosophy to collect data, and excavate data deeply with professional attitude to realize the shift from original traditional, passive and scattered fragmented management to modern, active and systematic gridding governance.[1]

\section{C.The mode of social governance is more consistent with} the times

For a long time, China's social management has been mainly to maintain social stability, this kind of top-down management and control type of social management is actually a kind of static social governance model, the kind of governance model not only hinders the flow of all social strata, affects the economic and social development, but also brings out a series of social conflicts. In the era of big data, profound changes have taken place in the social ecology, and social management information such as people, finances, materials, and events has become large and complex, the various social governance entities that undertake social governance duties can rely on social real-time data provided by big data technologies, predict social problems in advance, and then make social governance decisions, and evaluate, modify, and adjust real-time implementation of decisions, so that they can better respond to changes in the social governance environment, and then use the advantages of dynamic governance.

Under the traditional mode of social management, the government in the dominant position is a single management subject, the members of the society do not participate in the social management, and there is no effective communication and interaction mechanism, which causes many public interests to be difficult to realize.In the era of big data, the application of big data technology can promote the formation of an interactive communication mechanism between the government and the public, breaks the closedness of the traditional management model, greatly enhances the enthusiasm of interactive participation of various social governance entities, and realizes the main body of social governance, and contributes to an integrated and open governance system.

\section{NEW CHALLENGES FOR BIG}

\section{DATA SOCIAL GOVERNANCE}

\section{A.Low awareness of large data affects social governance}

Governments at all levels in the social decision-making and administration have put more emphasis on the traditional thinking of managing and neglecting services, which has led to a generally lower awareness of government and departments on social governance, and a lack of corresponding information platforms as support,due to the overlapping of responsibilities, the government and its departments have led to fragmented management of social governance, leading to its own intrinsic impetus to the development of big data-driven social governance; In addition, the enthusiasm of other social governance entities participating in social governance is not high, resulting in the use of big data to promote social governance innovation and lack of social foundation.

\section{B.Traditional social governance concept is confronted with} challenges

Traditional social governance concept highlights government-orientation concept, power-orientation concept and official-orientation concept. Government-orientation concept emphasizes that government is the one and only subject dominating social governance. Government plays the role of administrator, even the ruler. Under this conception, government, market, society and citizens are in unequal position and the distrust between them causes negative effects like malignant inflation of government institutions and low administrative efficiency. Power-orientation concept stresses that government is entitled to all rights in management, supervision and control of social public affairs, which leads to government's problems like offside, vacancy, dislocation, etc. Traditional social governance concepts lag far behind the time while social governance innovation in the big data era has its own value pursuit and action logic. The former lies in costruction of right-oriented society and the latter lies in construction of service-oriented government, forming an equal, 
negotiatory, and cooperative benign relationship between actors of social governance.

\section{C.Experience-based social governance method is}

\section{confronted with challenges}

For a long period, our data about economic and social studies mainly originates from sampled data, local data, and one-sided data, even totally depends on theories, hypothesis and values to explore laws of the unknown field. This approach estimating the overall situation according to a small amount of data, predcting the overall situation according to several cases, and inferring a series of measures according to some experience lays potential problems for social governance activities, which does not meet the current demand of social governance transition and innovation. At present, with the acceleration of social transition speed and increasingly deep social reform, the social complexity has become the new feature of social form. Obviously it is impossible to apply indiscriminate simple ways, and depending on social decision support system is really necessary. Accruately master the big data feature of governance to meet the diverse, diffrential needs people of different groups and social classes at different periods.

\section{D.Lack of relevant laws and regulations, information}

\section{security is threatened}

In the political life of the era of big data, the government has the vast majority of data and information resources, once information is leaked, the privacy of citizens will be made known to the public, this will give criminals an opportunity to exploit it. The opening up of data in the era of big data is also a general trend, which also makes the protection of citizens' personal information an urgent problem to solve. How to safeguard the security of information such as the protection of the privacy of countries, enterprises, and citizens, effectively control the risk of the collection, use, and sharing of big data, laws and regulations are not perfect. Without the relevant laws and regulations concerning big data, there is no guarantee that the data can be shared openly and not abused, and the main body of social governance has no way of knowing the boundaries of open and shared data resources, resulting in the improper opening up of data by managers, individuals, and companies, conflicts and the improvement of social governance capacity lack fundamental guarantees.[2]

\section{E.Existing e-government is difficult to adapt to big data} social governance requirements

After years of development and construction of e-government throughout the country, although the vertical and horizontal business system has been established, many of them are only the electronic flow of existing business processes, presenting the overall characteristics: heavy information, light data, heavy storage, light open. On the one hand, due to the lack of top-level design and enforceable standards for e-government construction, the development and construction of government affairs information systems is self-contained and takes place on their own. Due to lack of awareness of promoting the modernization of social governance, social governance data between the government and its departments cannot be interconnected. In addition, there is a lack of unified standards and norms, rules of operation and responsibility subject of data sharing from top to bottom, which leads to the low benefit of the comprehensive utilization of data and information of government and its departments, some even not, and a few departments even form the sectoral of property rights of information resources, which seriously hinders the timely sharing of the large data of social governance. At the same time, the format requirements of the data standards of different business departments are inconsistent, as a result, the data are fragmented and the integration is difficult. This not only severely restricts the sharing of big data resources, but also sets a solid obstacle for big data applications, on the other hand, the current application rate of government affairs app is too low, and data disclosure is lagging behind, the disclosure is mainly about policies on information items, not disclosure of data, and it is not data opening in the era of big data. Therefore, there is an urgent need to reengineer business processes based on the big data system network, and build an e-government system oriented to the people's livelihood, in order to improve administrative effectiveness and social governance capabilities. 


\section{SOLUTIONS TO INNOVATING SOCIAL GOVERNANCE}

\section{BY MEANS OF BIG DATA}

\section{A.Accelerating the cultivation of big data social}

\section{governance awareness}

The main leader of social governance should deeply understand the strategic position of big data resources and set up big data thinking. On the one hand, this requires us to strengthen knowledge dissemination and training at the grass-roots level and raise the overall awareness and application level of big data at the grassroots level. On the other hand, we must quickly build a supportive environment for the application of big data social governance. Pay attention to the use of big data in the work and give full play to its value in social governance.

\section{B.Revolution of social governance concepts: from}

\section{traditional type to modern type}

Revolution of social governance concepts is an important premise for social governance innovation. Promoting revolution of social governance concept is to shift from traditional type to modern type, specifically, shift from government-orientation concept to society-orientation concept, from power-orientation concept to right -orientation concept, official-orientation concept to citizen-orientation concept. As the suject mastering public power, government must correctly understand the origin and belonging of power, consciously prevent the abuse of power, dereliction and misconduct and stress the people-oriented concepts. During the process of social governance, government must repect people's willing and take safeguarding the interst of the broad masses as the core standard and measure of value, which means government should use power according to the law, deal with affairs according to regulations, totally break ideas of privilege and hierarchym and manifest service concept to each work.

\section{C.Transformation of Social Governance: From Experience to Science}

The transformation of social governance from an empirical to a scientific one is conducive to the real implementation of the advanced concept of "speaking with data", which is conducive to achieving a scientific social governance decision and a refined social governance process. The key to the transformation of social governance methods lies in the following: on the one hand, we must create an open governance atmosphere, improve the institutionalization, standardization, and informationization of open government affairs. Enterprises and social organizations must also join the information openness team and try their best to form a positive and mutually beneficial relationship with the government. On the other hand, to build a platform for open governance, the government should break through the shackles of empirical decision-making, rationalize the use of big data technology, and actively act as data collectors, transmitters, analysts, users, and sharers, transforming governance concepts into social governance, specific measures to ensure that governance initiatives are scientific and effective, to clarify the rational division of labor in the main body of social governance, not only to strengthen the leadership of the party committee, to play a leading role in the government, but also to encourage and support the orderly participation of all sectors of society. On the premise of respecting the legal norms, Germany and France are combined, rigidity and softness are combined, comprehensive management, economics, education, and other means of governance are used to achieve the orderly and full vitality of society. We should attach importance to the correlation analysis of social governance data, use big data technology to find the root of social problems, and insist on prevention first, and dynamic governance.

\section{D.Improving the relevant laws and regulations for the application of large data}

Faced with the threat of information security, and the lack of relevant laws and regulations, China should strengthen information security awareness, use the Internet rationally, and avoid disclosure of personal privacy; at the same time, it should expedite the development of laws and regulations concerning the protection of various types of data, the attribution of ownership rights, and the entire data industry chain, and clearly define the responsibilities, rights, and obligations of owning and managing data. Laws and regulations should also clarify the scope of the use of data by governments, enterprises, and organizations, specify the rules for use, and restrict the qualifications of users.In addition, laws 
and regulations should also stipulate relevant provisions for punishing leaks and other information that jeopardizes the privacy of other people's information, the public should be promoted and educated so that the use of information can be " there are laws to go by, the laws are observed."

\section{E.Building a unified and shared data platform to enhance} e-government capability

With the rapid economic and social changes in the era of big data, it has been difficult for traditional informationization to give full play to its support and leading role in social construction. Therefore, cleaning up and integrating data from various departments, and resolving fragmentation of data resources have become an important prerequisite for social governance of big data.Therefore, governments at all levels urgently need to build a unified and shared data platform, to achieve unity and sharing of data standards and formats, and on this basis, integrate relevant functional organizations, such as information centers of various departments and various government information platforms. The establishment of a big data resource management institution not only ensures the consistency and authority of data resources, but also breaks down the information barriers of various departments.

At the same time, using weibo, we chat, and mobile app to connect the government with the public, to achieve online and offline communication and interaction, so that the government's public services can be more personalized and refined, and better meet public needs. On the other hand, it is also possible to use the evaluation of the public in the online community, to know the effect and quality of the service,so as to find out where improvements need to be made. The establishment of a public-to-consumer-oriented online and offline closed-loop work flow and the creation of integrated governance online and offline, can effectively avoid the traditional top-down one-way service and decision-making malaise.

\section{CONCLUSION}

Big data provides revolutionary weapon for national governance system. In the age of big data, innovation of social governance is an important link to realize modernization of the country's governance system and governance capability, also it is the necessary requirement of a society with vitality, harmony and order. Cooperative governance of all governance subjects is of great significance for guaranteeing and improving people's livelihood, promoting social fairness and justice, preventing and eliminating social contraditions, protecting the public security, enhancing the Party's leadership, buiding a harmonious society, and modernizing the country's governance system and governance capability.

\section{ACKNOWLEDGMENT}

1. General project of The National Social Science Fund of China (18BSH055).

2. Yunnan Philosophy and Social Science Planning Project (YB2017036).

\section{REFERENCES}

[1] Huo Xiurong. Using big data to promote the innovation of social governance $[\mathrm{J}]$. Journal of Chongqing Industry and Trade Polytechnic, 2016 (4). (In Chinese)

[2] Liu Yanhan. Chinese government's public governance innovation. Chinese government's public governance innovation. [J]. Cooperation of economy and technology. 2017(15):182-183. (In Chinese)

[3] Frankel F.and Reid R., 2008. "Big Data: Distilling Meaning from Data. "Nature. 45( 7209) : 30 .

[4] Ginsberg.J., et al. 2009."Detecting Influenza Epidemics Using Search Engine Query Data. "Nature. 457( 7232) : 14

[5] Hey T., et al. , 2009. The Fourth Paradigm: Data - Intensive Scientific Discovery( Vol. 1). R edmond, WA: Microsoft R esearch.

[6] James, M. , et al. 2011. Big Data: the Next Frontier for Innovation, Competition and Productivity. TheMc Kinsey Global Institute

[7] Liu Shuyi , Research on Government Governance Innovation in Big Data Era, Yunnan University. (In Chinese)

[8] Mundial, F.E. 2012. Big Data, Big Impact: New Possibilities for International Development. World Economic Forum.

[9] Ni Kaomeng, Governance of the Big Data Era.[J]. Decision-Making \& Consultancy. ,2013(06). (In Chinese)

[10] Labrinidis A, Jagadish H V. Challenges and opportunities with big data[J]. Proceedings of the Vldb Endowment, 2011, 5(12):2032-2033

[11] Wang Shan, Chinese Government Governance Capability and Public Governance Innovation in the Era of Big Data . [J]. QiuShi . 2017.1. (In Chinese)

[12] Zhu Min, Research on Public Governance Innovation in the Mobile Internet Big Data Era . [J] . New Economy Weekly . 2017.21. (In Chinese) 